\title{
BAHASA INDONESIA-ENGLISH CODE-MIXING IN WRITING BUSINESS EMAILS: UNDERSTANDING THE COMMUNICATIVE PURPOSE
}

\author{
Robby Andre \\ Master of Linguistics, Faculty of Humanities, Airlangga University \\ Jl. Dharmawangsa Dalam, Surabaya 60286, Indonesia \\ robby.andre-2016@fib.unair.ac.id
}

Received: $24^{\text {th }}$ April 2017/Revised: $12^{\text {th }}$ November 2017/Accepted: $12^{\text {th }}$ December 2017

How to Cite: Andre, R. (2018). Bahasa Indonesia-English code-mixing in writing business emails: Understanding the communicative purpose. Lingua Cultura, 12(2). 117-121. https://doi.org/10.21512/lc.v12i2.3733

\begin{abstract}
The research had two objectives, those were to investigate the use of code-mixing in the business emails which could be categorized as asynchronous computer-mediated communication, and to calculate the most prevalent occurrences of codemixing in the business emails. The data were gathered from the business emails of Corporate Sales Officer in The British Institute Surabaya and its corporate clients from January to June 2017. Code-mixing typology acted as the primary tool in identifying and classifying the code-mixing in the data. The analysis of data yielded a total of 209 code-mixing occurrences. From the result, it can be seen that code-mixing insertion is ranked as the most prevalent occurrences of code-mixing with a total of 115 occurrences (55,02\%). It is followed by code-mixing congruent lexicalization with 78 occurrences (37,32\%), and code-mixing alternation with 16 occurrences $(7,66 \%)$. Furthermore, the result of the study shows that the occurrences of code-mixing categories in the business emails may have some communicative purposes, such as emphasizing the main idea of the utterances or referring to the specific lexical items which deal with the knowledge of certain fields.
\end{abstract}

Keywords: code-mixing, computer-mediated communication, asynchronous communication, business emails

\section{INTRODUCTION}

Code-mixing as communicative competence is majorly examined in its connection to the bilingualism. In this case, this communicative competence plays an important role in providing opportunities to individuals in expressing their feelings or thoughts and shaping their identity. This communicative competence also serves some assistance to the individuals in fulfilling the satisfaction of their personal and social needs through the languages that they use (Muysken, 2000). The phenomena of code-mixing of several languages have long intrigued researchers who have scrutinized what are the possible reasons that trigger such occurrences (Cárdenas-Claros \& Isharyanti, 2009; Goldbarg, 2009; Huang, 2009; Senaratne, 2009; Das \& Gambäck, 2013; Singh \& Kanskar, 2013; Sutrismi, 2014; Bukhari et al., 2015; Halim, Nadri, \& Mahmood, 2015). However, a few studies that have been conducted only focus on the analysis in the face-to-face interaction (Senaratne, 2009). Some studies analyze the occurrences of code-mixing in the context of computer-mediated communication. It further analyzes the informal setting like internet chatting, or facebook and twitter status (Cárdenas-Claros \& Isharyanti, 2009; Huang, 2009; Sutrismi, 2014; Bukhari et al., 2015; Halim, Nadri, \& Mahmood, 2015).

Code-mixing has been defined in numerous definitions from the several past decades. In early studies, code-mixing is defined as an 'abnormal behavior'. According to Haugen (1953), except in abnormal cases, speakers have not been observed to draw freely from two languages at once and at any given moment they are speaking one language. Kachru (1978) has defined code-mixing as a strategy utilized by the speakers in transferring linguistic units from one language to another. This might result in a restricted or not so restricted code of linguistic repertoire. It includes mixing of lexical items, full sentences, or the embedding of idioms. In this case, there will be no limit to insertion.

Moreover, Blanc and Hamers (2000) have defined code-mixing as a strategy that transferred elements of all linguistic levels and units ranging from a lexical item to a sentence. They also examine that the occurrence of code-mixing happens due to the lack of competence. Furthermore, Muysken (2000) has defined code-mixing as an intra-sentential code switching or intra-sentential codealternation that occurred due to the use of two or more languages below clause level within one social situation. Similarly, Gardner-Chloros (2009) has asserted that codemixing occurs because of the innovation created by the speakers in inserting the content words into the grammatical structure of another language.

Based on the given definitions of code-mixing, it is obvious that there is a similarity among those definitions. 
Most of the researchers define code-mixing as a transfer of linguistic items, in most instances content words or constituent insertions from one language to another. Besides that, most of the given definitions also mention about the insertion of the certain word from one language to another. It can result in the asymmetrical involvement of languages in the bilingual lexicon.

According to Muysken (2000), there are three major categories in code-mixing: insertion, alternation, and congruent lexicalization. The first category of code-mixing is the insertion. Based on Muysken (2000), insertion usually occurs when there is the incorporation of lexical items from one language to another. Moreover, the term 'insertion' that is proposed by Muysken (2000) corresponds to the notion of 'transference' by Clyne (1991). Figure 1 illustrates a graphic representation of insertion in code-mixing.

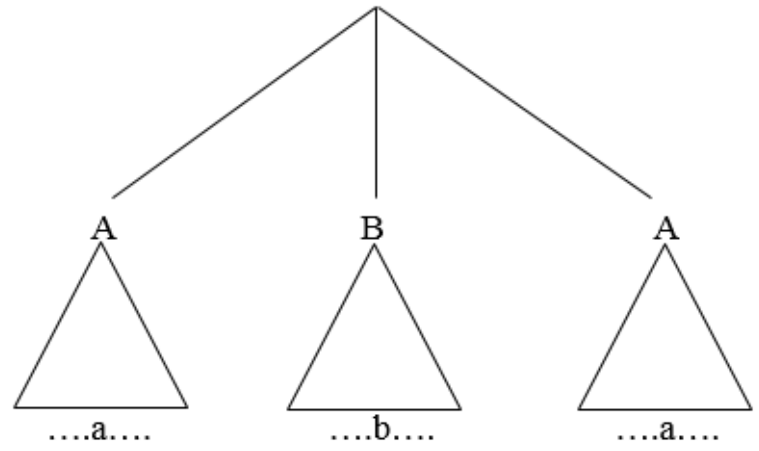

Figure 1 Illustration of Code-Mixing Insertion (Source: Muysken, 2000)

In Figure 1, the word 'a' stands for lexical items of the first language. Meanwhile ' $b$ ' represents lexical items of the second language that has been inserted in the utterance by the speaker. The example of the code-mixing insertion can be seen as follows:

"Mohon bantuannya untuk direschedule kelas saya." (I need your help to reschedule my class.)

The example is taken from one of the business emails by one of the corporate clients of TBI Surabaya. In this case, the client asks for help from TBI's Corporate Sales Officer to reschedule his English class. The shared professional background of TBI corporate client and Corporate Sales Officer in the specific language is the reason for the client to unconsciously insert an English lexical item into Bahasa Indonesia written conversation.

Second, Muysken (2000) has defined the second structure as the two languages are alternated indistinctively both at the grammatical and lexical level. These kinds of structures are categorized as code-mixing alternation. Figure 2 illustrates the code-mixing alternation.

In Figure 2, A and B are the representation of the two languages. It represents the code-mixing alternation in the form of utterances produced by the speaker. The example is the representation of code-mixing alternation between Bahasa Indonesia and English. It can be seen as follows.

"I think, kita lebih fokus terhadap teknik pengumpulan data dalam penelitian ini."

(I think, we better focus on the technique of data collection in this research.)
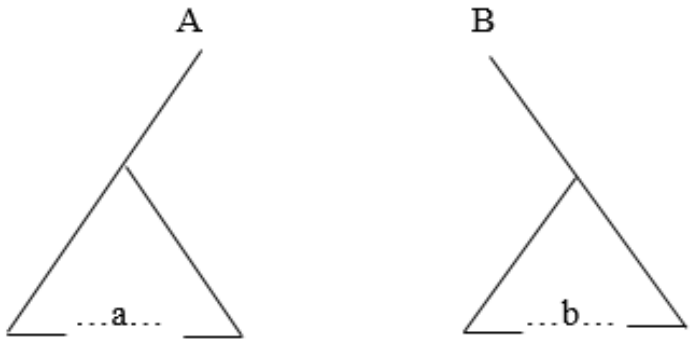

Figure 2 Illustration of Code-Mixing Alternation (Source: Muysken, 2000)

According to the example, the speaker uses English in the first part of his/her utterance. Interestingly, when it comes to the notion of the technique of data collection of the research that the speaker may currently work on, he/ she switches the code to Bahasa Indonesia. In this case, the speaker may want to underline the main point of his/her utterance by utilizing his/her first language.

The last category of code-mixing proposed is codemixing congruent lexicalization. In this category, the speaker tends to combine two languages in term of their grammatical structures. It can be lexically filled with the lexical items from either language. Figure 3 shows the codemixing congruent lexicalization.

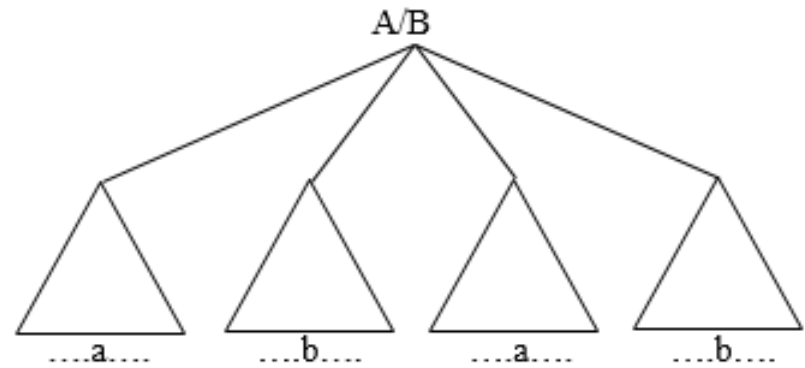

Figure 3 Illustration of Code-Mixing

Congruent Lexicalization

(Source: Muysken, 2000)

$\mathrm{A}$ and $\mathrm{B}$ are the representation of the two languages. It represents the code-mixing congruent lexicalization in the form of utterances produced by the speaker. To understand this code-mixing, the researcher provides the example of this code mixing as follows.

"Meeting hari ini akan membahas tentang urgent agenda yang akan dilakukan within this week"

(Today's meeting will discuss about the urgent agenda that will be done within this week)

Based on the example, the speaker utilizes Bahasa Indonesia and English in his/her utterance. The speaker talks about the meeting that will discuss the urgent agenda. It needs to be done within this week.

Moreover, the occurrences of code-mixing can be examined in this study by using computer-mediated communication. Herring and Androutsopoulos (2015) have asserted that computer-mediated communication is basically a communication that commonly takes place among people. It is conducted through the computers as the media of the communication. This kind of communication is also valued as one of the alternatives in communication. 
It provides computer users with some various options such as chat rooms, blogs, instantly delivered messages through the internet, and others. In addition, computer-mediated communication is essentially utilized as the media of communication that can be used by the computer users based on their needs.

Herring (1996) has classified the computermediated communication into two categories based on the term of delay. Those are synchronous computermediated communication and asynchronous computermediated communication. Synchronous computer-mediated communication occurs in the real time. It could be further seen from the communication through the relay chats, chat rooms, instant messaging, and tweets. On the contrary, asynchronous computer-mediated communication allows the computer-mediated communication users to access the media at a different time. This could be done through emails, blogs, and wikis.

Crystal (2006) has suggested that these forms of computer-mediated communication might trigger an evolution of spoken and written language. Essentially, language is based on its genre which is spoken and written. In this case, written language tends to concentrate on the structural complexity, formality, and abstraction. Meanwhile, spoken language can be characterized as a more dependent and structurally simpler language. Herring and Androutsopoulos (2015) have emphasized that in the environment of computer-mediated communication, one of the most significant elements of language is the combination of the spoken and written language. The written communications in the computer-mediated communication environments are unclear. It is due to the combination of the spoken and written genre. This also occurs in the asynchronous computer-mediated communication where the computer users sometimes combine both genres to emphasize the point to the other users (Crystal, 2006). This is done by the users to achieve the goal of the communication and make the communication work effectively.

Most studies in code-mixing in computer-mediated communication have analyzed synchronous communication. One of the earliest studies which examined code-switching and code-mixing in computer-mediated communication environments is Cárdenas-Claros and Isharyanti (2009). They analyze English, Spanish, and Bahasa Indonesia use in the Internet chatroom. Those are uttered by 12 nonnative speakers of English from Spanish and Indonesian. The finding has suggested that code-mixing become the second most common code used by the speakers in this study. Moreover, among the categories of code-mixing, the code-mixing alternation is ranked as the highest categories in the internet chatroom of the participants. The highest number of code-mixing insertion in the internet chatroom by the participants is because code-mixing insertion does not require a high language proficiency at a lexical level compared to the code-mixing alternation and congruent lexicalization. Those require the speaker to master the language at the grammatical and semantic levels fully.

Das and Gambäck (2013) have investigated the characteristic of code-mixing in social media texts of English-Bengali and English-Hindi. They gather the data from two corpora (English-Bengali and English-Hindi). The result of this study shows that reduplication is ranked as the most common code-mixing in English-Bengali and English-Hindi. This finding supports the finding of the other studies which find that reduplication is the most common code-mixing in South-East Asian social media texts.
Sutrismi (2014) has examined the code-mixing in social media posts (Facebook) of Indonesian Youngsters. The data is gathered from Facebook posts of Indonesian Youngsters, and they further classify it into several categories based on Suwito's theory. The result suggests that there are six types of linguistic forms of code-mixing in the data. Those are single word and compound word as the highest type of code-mixing $(63,16 \%)$, noun phrase, verb phrase and preposition phrase $(18,42 \%)$, hybrid $(9,21 \%)$, clause $(5,26 \%)$, reduplication $(2,63 \%)$, and blending $(1,32 \%)$.

However, there is a similarity among the previous studies. They mainly analyze the types of code-mixing in synchronous communication. Hence, this study, by contrast, utilizes business emails as the object of this study to examine the code-mixing in the emails. Furthermore, to gain more insight into the various types of code-mixing and their frequencies, this study aims at identifying the types of code-mixing and calculating the most prevalent codemixing that occurred in the business emails.

Reflecting the current condition in Indonesia, code-mixing may become one of the most criticized and undervalued linguistic phenomena. This phenomenon remains the subject of controversial debate in linguistic areas. Despite its popularity and the phenomenal usage by most speakers, many believe that in mixing two languages, speakers are not speaking either language properly. Due to this argument, the researcher can assume that the underlying significance of code-mixing as a mechanism of language change is being ignored.

Related to the object of this study, the researcher scrutinizes the phenomena related to the code-mixing in the business emails. These business emails are further gathered from one of the English provider institutions in Indonesia named as The British Institute (TBI). The emails are further taken from the interaction between the Corporate Sales Officers of TBI and their corporate clients. Moreover, the study is conducted to fulfill the gap between the studies that have been conducted in investigating the code-mixing in social media texts. It only focuses on the informal setting of the interaction between the users. Therefore, the present study is expected to provide the types of code-mixing of Bahasa Indonesia-English in business emails or more formal situation.

In relation to the background of the study, the researcher is curious to formulate two research questions. First, it is what the categories of code-mixing are in the business emails of Corporate Sales Officers of TBI and their corporate clients. Second is what the most prevalent category of code-mixing is in the business emails of Corporate Sales Officers of TBI and their corporate clients.

Through the research questions that are formulated in the study, the researcher sees the necessity to dispose of objectives of the study. There are two objectives in the study. First is to figure out what categories of code-mixing in the business emails of Corporate Sales Officers of TBI and their corporate clients. Second is to find out the most prevalent category of code-mixing in the business emails of Corporate Sales Officers of TBI and their corporate clients.

\section{METHODS}

The data are gathered from business emails of Corporate Sales Officer of TBI Surabaya with the corporate clients. The emails are gathered from January to June 2017 or about 257 emails approximately. The gathered emails 
as the data in the study are the interactions between the Corporate Sales Officer of TBI Surabaya as the professional representative of the institution and its corporate clients who take the in-house training programme in TBI Surabaya.

The analysis of the data begins with the identification of code-mixing by highlighting the words, phrase, or sentences. The researcher also uses the code-mixing typology proposed by Muysken (2000) to classify the codemixing category. Moreover, the calculation of code-mixing occurrences and frequencies are conducted to figure out the most prevalent code-mixing in the business emails of Corporate Sales Officer of TBI Surabaya with the corporate clients. Afterward, the discussion about the most prevalent code-mixing is provided by the researcher to gain depth knowledge about the possible reason which triggers the occurrences of the code-mixing. Moreover, in relation to the data analysis, the researcher uses computer-mediated communication.

\section{RESULTS AND DISCUSSIONS}

According to data, the researcher finds the occurrences of three categories of code-mixing proposed by Muysken (2000). In this case, results for code-mixing in the data show that from 257 emails, it consists of 3.223 words. There are 115 occurrences $(55,02 \%)$ correspond to the category of insertion. Moreover, 16 occurrences $(7,66 \%)$ fulfill the definition of alternation, and 78 occurrences $(37,32 \%)$ are congruent lexicalization. Table 1 provides the distribution and the percentage of the occurrences of codemixing categories.

Table 1 Distribution of the Occurrences of Code-Mixing Classification

\begin{tabular}{llcc}
\hline No & $\begin{array}{l}\text { Code-Mixing } \\
\text { Categories }\end{array}$ & $\begin{array}{l}\text { Total } \\
\text { Occurrences of } \\
\text { Each Category }\end{array}$ & Percentage \\
\hline 1. & Code-Mixing Insertion & 115 & 55,02 \\
2. & $\begin{array}{l}\text { Code-Mixing } \\
\text { Congruent }\end{array}$ & 78 & 37,32 \\
& $\begin{array}{l}\text { Lexicalization } \\
\text { Code-Mixing } \\
\end{array}$ & 16 & 7,66 \\
\hline & \multicolumn{1}{c}{ Alternation } & \\
\hline
\end{tabular}

As presented in Table 1, code-mixing insertion $(55,02 \%)$ is the most prevalent occurrences of code-mixing categories. It occurs in the business emails compared to code-mixing congruent lexicalization that corresponds to $37,02 \%$. Meanwhile, code-mixing alternation has 7,66\%. This result proposes that code-mixing insertion as the most prevalent occurrences may reflect the communicative purpose of the speakers. The speaker sometimes inserts certain words to the utterance to strengthen the main notion of the arguments.

Moreover, the result of the study in term of the occurrences of code-mixing insertion supports the findings of Cárdenas-Claros and Isharyanti (2009). The case of insertion of a word from one language to another requires minimum competence at a lexical level compared to the congruent lexicalization or alternation. Those require the speaker to master the language at the grammatical and semantic levels fully.
According to the data, the researcher finds 115 occurrences related to the code-mixing insertion. Among those, there are 98 occurrences $(85,21 \%)$ categorized as a noun. This result supports the findings of Cárdenas-Claros and Isharyanti (2009). They also found that in the codemixing insertions, noun contributes the highest number compared to the other word classes. This may occur because the data of the study are from business emails. The major topics of the discussion talk about business and financial situation that cover various specific nouns. Furthermore, Das and Gambäck (2013) have also emphasized that the use of specific nouns become one of the possible reasons for the speakers to do the code-mixing insertion in their utterances. Besides that, the code-mixing insertion that contributes the highest number in terms of occurrences also may deal with the language proficiency of the speakers. In this case, the speaker tends to use insertion because it only requires a minimum level of language proficiency compared to the other code-mixing categories. The other code-mixing categories require the speaker to master the grammatical and semantic level of a language to create a well-comprehended utterance.

Moreover, the occurrences of code-mixing insertion may be triggered by the speaker's intention to highlight the main point the utterances. The speaker utilizes the lexical items from another language. For example, "berikut terlampir adalah revisi dari draft invoice TBI Surabaya" or "terima kasih atas penawaran dan kerjasamanya yang sangat baik serta fast response" ("the following attachment is a revision of the invoice draft of TBI Surabaya" or "thank you for the offers and the excellent and fast response cooperation"). From both examples, the phrase 'draft invoice' and 'fast response' are the main point of the utterances. In this case, the speakers tend to use English in her/his utterances to highlight the main point of his/her utterances. This result is also in line with the other findings of the previous studies (Cárdenas-Claros \& Isharyanti, 2009; Das \& Gambäck, 2013; Sutrismi, 2014). The use of lexical items from another language occurs because speaker wants to highlight the main point of the utterances.

Then, code-mixing congruent lexicalization is ranked as the second most prevalent occurrences of codemixing in the study. Muysken (2000) has defined codemixing congruent lexicalization as the combination of two languages regarding their grammatical structures. It could be lexically filled with the lexical items from either language. Based on the data, the occurrences of code-mixing congruent lexicalization are 78 occurrences (37,32\%). In code-mixing congruent lexicalization, the verb is commonly found in the data about 48 out of $78(61,53 \%)$. This result is in line with the findings by Sutrismi (2014). Sutrismi (2014) has agreed that verb contributes the highest number of occurrences among the other word classes.

The occurrence of code-mixing congruent lexicalization is dominated by the verb. It may happen because of the goal of the texts. The data are regarding some business correspondences. Therefore, the speakers may attempt to communicate some specific aspects by utilizing English to assist the audience in understanding the speaker's notion. For example, "Mohon infonya kapan untuk invoice ini bisa di-submit ke HMS" or "Sementara ini mohon untuk di-hold terlebih dahulu sampai surat tersebut bisa kami kirimkan ke Ibu" ("Please inform us when this invoice can be submitted to HMS" or "In the meantime, please hold the letter first until we can send it to you). In both examples, the speaker tends to utilize code-mixing congruent 
lexicalization to express his/her concern about the topics of conversation through the emails. 'Di-submit' and 'di-hold' are the real examples of congruent lexicalization. In those examples, the speaker tends to combine the grammatical and lexical aspects between Bahasa Indonesia and English by inserting the following words 'submit' and 'hold'. It utilizes the passive voice of Bahasa Indonesia by combining those words with the prefix ' $d i$-'. Therefore, the words ' $d i$-submit' and 'di-hold' sounds are accepted in Bahasa Indonesia.

Code-mixing alternation is the next in the occurrences of code-mixing categories proposed by Muysken (2000). However, it occurs at the lower rate than code-mixing insertion or code-mixing congruent lexicalization. It occurs only 16 occurrences $(7,66 \%)$. This result is contradicted by the findings of Cárdenas-Claros and Isharyanti (2009). They confirmed that there is no occurrence of code-mixing alternation in their study. This may happen because data that are utilized in the study is quite different from the data of Cárdenas-Claros and Isharyanti (2009). This study utilizes business emails as the main data where they can be categorized as asynchronous communication. Meanwhile, the data of Cárdenas-Claros and Isharyanti (2009) use MSN chats as the main data where it is classified as synchronous communication. Besides that, the form of language between this study and previous study may also affect the occurrences of code-mixing alternation. In this case, the data of this study mostly uses formal language, while the data of the previous study utilizes everyday language. Furthermore, the language proficiency of the speakers may also affect the occurrences of code-mixing alternation. The way the speakers communicate in the Internet chatting is not complicated compared to the communication through emails which mostly discuss the business correspondence. The speakers need to master grammatical and semantic level to create well-structured utterances to create a smooth communication with the other speakers.

\section{CONCLUSIONS}

Although the results from this study cannot be generalized about Indonesians' code choice, several results support previous studies on code-mixing in computermediated communication. Furthermore, the results suggest that there are various code-mixing in the communication through business emails.

The most prevalent code-mixing is the code-mixing insertion. Meanwhile, the second most prevalent codemixing is code-mixing congruent lexicalization, and the least prevalent code-mixing is code-mixing alternation. This may happen due to the language proficiency of the speakers. As stated before, the code-mixing insertion becomes the most prevalent code-mixing in the data because the speaker only needs a minimal requirement of language proficiency compared to the code-mixing congruent lexicalization or alternation. Those require the speaker to master the language from grammatical and semantic aspects. Further study in comparing code-mixing occurrences based on gender and age groups is critically needed. It may assist the researchers to gain a better understanding of these phenomena, specifically, to the computer-mediated communication or asynchronous communication.

\section{REFERENCES}

Blanc, M., \& Hamers, J. F. (2000). Bilinguality and bilingualism ( $2^{\text {nd }}$ ed.). Cambridge: Cambridge University Press.

Bukhari, N. I. B. A., Anuar, A. F., Khazin, K. M., \& Abdul, T. M. F. B. T. (2015). English-Malay code-mixing innovation in Facebook among Malaysian University students. Researchers World, 6(4), 1-10.

Cárdenas-Claros, M. S., \& Isharyanti, N. (2009). Code switching and code mixing in Internet chatting: Between, 'yes', 'ya', and 'si' A Case Study. The Jalt Call Journal, 5(3), 67-78.

Clyne, M. G. (1991). Community languages: The Australian experience. Cambridge: Cambridge University Press.

Crystal, D. (2006). Language and the Internet (2 ${ }^{\text {nd }}$ ed.). Cambridge: Cambridge University Press.

Das, A., \& Gambäck, B. (2013). Code-mixing in social media text: The last language identification frontier? TAL, 54(3), 41-64.

Gardner-Chloros, P. (2009). Code-switching. Cambridge: Cambridge University Press.

Goldbarg, R. N. (2009). Spanish-English codeswitching in email communication. Language@Internet, 6(3), $1-21$.

Halim, H., Nadri, H., \& Mahmood, F. (2015). Code-mixing on Facebook among Malaysian TESL students. Advances in Social Sciences Research Journal, 2(5), 27-33.

Haugen, E. (1953). The Norwegian language in America: A study in bilingual behavior. Philadelphia: University of Pennsylvania Press.

Herring, S. C. (1996). Computer-mediated communication: Linguistic, social and cross-cultural perspectives. Amsterdam: John Benjamins.

Herring, S. C., \& Androutsopoulos, J. (2015). Computermediated discourse 2.0. In D. Tannen, H. E. Hamilton, \& D. Schiffrin (Eds.), The Handbook of Discourse Analysis (pp. 127-151). Oxford: WileyBlackwell.

Huang, D. L. (2009). Language use in asynchronous computer-mediated communication in Taiwan. Australian Review of Applied Linguistics, 32(2), 12.1-12.22.

Kachru, B. B. (1978). Code-Mixing as a communicative strategy. In J. Alatis (Ed.), International Dimensions of Bilingual Education (pp. 107-124). Washington, D. C.: Georgetown University Press.

Muysken, P. (2000). Bilingual speech: A typology of code mixing. Cambridge: Cambridge University Press.

Senaratne, C. D. (2009). Sinhala-English code-mixing in Sri Lanka: A sociolinguistic study (Ph.D. Dissertation).

Singh, A., \& Kanskar, A. (2013). POS tagging of HindiEnglish code mixed text from social media. International Journal of Science and Research (IJSR), 5(10), 1018-1021.

Sutrismi. (2014). The use of Indonesian English code mixing in social media networking (Facebook) by Indonesian youngsters (Undergraduate Thesis). 